\title{
AVALIAÇÃO PÓS-OCUPAÇÃO EM CRECHES PROINFÂNCIA: MÉTODOS, INSTRUMENTOS E APLICAÇÃO
}

\section{EVALUATION POST-OCCUPATION IN PROCHILDHOOD PRESCHOOL: METHODS, INSTRUMENTS AND APPLICATION}

Bruna Cristina Lermen ${ }^{1}$, Acad.

Danieli Faccin Bernardi², Acad.

Maiara Aparecida Giacomini ${ }^{3}$, Acad.

Cristhian Moreira Brum ${ }^{4}$, D.Sc.

(1) Universidade Regional Integrada do Alto Uruguai e das Missões e-mail: brunalermen@hotmail.com

(2) Universidade Regional Integrada do Alto Uruguai e das Missões e-mail: danielifaccin@hotmail.com

(3) Universidade Regional Integrada do Alto Uruguai e das Missões e-mail: mai.giacomini@hotmail.com

(4) Universidade Regional Integrada do Alto Uruguai e das Missões e-mail: $\underline{\text { c.brum@outlook.com }}$

Palavras-chave: PROINFÂNCIA, Avaliação Pós-Ocupação, método

Objetivando avaliar se o projeto arquitetônico é adequado ao processo pedagógico, o artigo apresenta o estudo de caso realizado em quatro creches PROINFÂNCIA localizadas na região noroeste do estado do RS, a partir de técnicas de Avaliação Pós-Ocupação, dando ênfase a metodologia e técnicas adotadas quando da investigação.

Key-words: Prochildhood, Evaluation Post-Occupation, method

In order to evaluate if the architectural project is adequate to the pedagogical process, the article presents a case study carried out in four Prochildhood preschool located in the northwest region of the State of Rio Grande do Sul, Brazil, based on post-occupation evaluation techniques, with emphasis on the methodology and techniques adopted when investigating. 


\section{$16^{\circ}$ \\ ERGODESIGN USIHC CINAHPA}

\section{Introdução}

O presente artigo é o produto final da disciplina de Avaliação Pós Ocupação A, no curso de Arquitetura e Urbanismo, da Universidade Regional Integrada do Alto Uruguai e das Missões, campus de Frederico Westphalen. Seu principal objetivo é a compreensão, a construção e a aplicação dos métodos e ferramentas que são utilizados na Avaliação Pós-Ocupação (APO).

Sabe-se que um ambiente escolar adequado, tanto funcional quanto capaz de proporcionar possibilidades aos seus alunos, é de fundamental importância para o desenvolvimento educacional do ser humano. A arquitetura está intimamente ligada com as sensações que um ambiente transmite aos seus usuários, sejam eles funcionários, alunos ou pessoas que tem um contato superficial com a edificação e seu entorno.

Vários fatores mostram-se necessários para que uma edificação, neste caso, um ambiente escolar atinja seus objetivos, entre eles a associação de conforto para os usuários, a disposição correta dos ambientes internos e suas dimensões espaciais.

Este artigo tem como finalidade avaliar, buscando identificar problemas e qualidades de creches padrão federal PROINFÂNCIA, modelo C, em quatro cidades localizadas no norte do Rio Grande do Sul, sendo elas: Caiçara; Jaboticaba; Pinheirinho do Vale; e Vicente Dutra.

\section{Referencial Teórico}

O referencial teórico deste artigo se dá a partir do embasamento em leis e autores conhecidos que proporcionam maior entendimento sobre a avaliação realizada bem como sobre os motivos relacionados com a escolha deste tema.

Segundo o Estatuto da Criança e do Adolescente ECA, lei n 8.069/1990, artigo 53, é direito da criança e do adolescente acesso à educação, em escola pública e gratuita; o artigo 54 diz que é dever do estado assegurar a criança o atendimento em creche e pré-escola às crianças de zero a seis $16^{\circ}$ Ergodesign - Congresso Internacional de Ergonomia e Usabilidade de Interfaces Humano Tecnológica: Produto, Informações Ambientes Construídos e Transporte

$16^{\circ}$ USIHC - Congresso Internacional de Ergonomia e Usabilidade de Interfaces Humano Computador

CINAHPA | 2017 - Congresso Internacional de Ambientes Hipermídia para Aprendizagem.

anos de idade (ECA,1990).

Sabendo-se que a educação pública é um direito e que os municípios bem como o governo estadual e federal devem disponibilizar a oferta de instituições de ensino, o Ministério da Educação, através do Fundo Nacional de Desenvolvimento da Educação (FNDE), criou o Programa Nacional de Reestruturação e Aquisição de equipamentos para a Rede Escolar Pública de Educação Infantil (PROINFÂNCIA), pela resolução ${ }^{\circ} 6$, de 24 de abril de 2007 e faz parte das ações do Plano de Desenvolvimento da Educação (PDE). Desta forma, o principal objetivo desse programa é "prestar assistência financeira ao Distrito Federal e aos municípios visando garantir o acesso de crianças a creches e escolas de educação infantil da rede pública" (MARCELINO, 2014, p.15).

A Avaliação Pós-Ocupação (APO), na medida em que consiste em um conjunto de métodos e técnicas para a análise do desempenho de ambientes construídos e em uso do ponto de vista tanto de especialistas como dos seus usuários (CAMBIAGHI, 2007), desta forma faz-se necessário aplicar tais métodos e técnicas na avaliação de Proinfâncias, modelo C, construídas com fatores de influência externos diferentes.

Conforme Ornstein (1992 apud TAVARES, 2012, p.07), há uma crescente importância do trabalho avaliativo, enquanto subsídio a novos projetos, ou face a programas de reforma e manutenção do espaço construído.

Este artigo possui caráter avaliativo e busca detectar pontos positivos ou negativos referentes as Proinfâncias analisadas, através de Multimétodos determinados. A partir desta compatibilização de informações, poder-se-á ter um quadro geral, e assim definir resultados e diretrizes.

\section{Materiais e métodos}

A metodologia utilizada na avaliação do desempenho dos objetos de estudos visou a aplicação de uma abordagem multimétodos onde, a partir da visita as creches PROINFÂNCIA foram selecionadas quatro técnicas, a saber: análise
Realização:

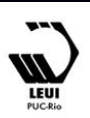




\section{$16^{\circ}$ \\ ERGODESIGN USIHC CINAHPA}

Walktrough, Mapa Comportamental, Poema dos Desejos e Questionários, sendo estas duas de abordagem direta entre usuários e pesquisadores/investigadores.

Desta forma, o desenvolvimento da avaliação buscou responder, basicamente, as seguintes inquietações motivadoras da pesquisa: Existe uma relação significativa entre organização espacial, interações sociais e desenvolvimento infantil? É o projeto arquitetônico apresentado adequado ao processo pedagógico? De que forma a solução espacial e implantação da edificação pode potencializar ou prejudicar o processo de aprendizagem e vivência?

\subsection{Análise Walktrough}

A análise da situação existente baseou-se no método walkthrough, de forma a levantar as características físico-espaciais da escola, bem como avaliar seu desempenho sobre aspectos técnicos - construtivos, estéticos-compositivos, acessibilidade e contextuais ambientais. A partir deste método realizou-se uma análise de cada ambiente que compõe a edificação, bem como alterações sofridas no mesmo, sendo as mesmas regidas por um roteiro check-list previamente elaborado (figura 01), e seus resultados foram registrados em fichas de inventário ambiental contendo data e horário do levantamento, área e pé-direito aproximados, número de ocupantes, croquis do layout, caracterização dos revestimentos - pisos, paredes e tetos, fotos e comentários gerais de cada ambiente analisado.

\begin{tabular}{|l|l|l|l|l|l|}
\hline Aspectos estéticos-compositivos & A & B & C & D & E \\
\hline Aparência externa & & & & & \\
\hline Aparência interna & & & & & \\
\hline Cores & & & & & \\
\hline Texturas & & & & & \\
\hline Formas & & & & & \\
\hline Proporções & & & & & \\
\hline Principios compositivos & & & & & \\
\hline Comentários: & \multicolumn{5}{l}{}
\end{tabular}

Figura 01: Exemplo de checklist adotado para investigação, por aspecto analisado, sendo A-muito bom, B-bom, C-razóavel, D-ruim, E- muito ruim. Fonte: dados da pesquisa, 2016 $16^{\circ}$ Ergodesign - Congresso Internacional de Ergonomia e Usabilidade de Interfaces Humano Tecnológica: Produto, Informações Ambientes Construídos e Transporte

$16^{\circ}$ USIHC - Congresso Internacional de Ergonomia e Usabilidade de Interfaces Humano Computador

CINAHPA | 2017 - Congresso Internacional de Ambientes Hipermídia para Aprendizagem.

\subsection{Mapa comportamental}

Conforme Ornstein (1995 apud GALVÃO, 2007,p.70), mapa comportamental se resume a uma técnica de observação com objetivo de identificar atividades e comportamentos que se repetem no tempo ou no espaço. Desta forma, a aplicação desse instrumento pode estar centrada no lugar ou no indivíduo.

Como o objetivo principal do uso desse instrumento neste trabalho consistiu em avaliar os principais locais de vivência e de recreação da escola e as relações de apropriação, seu emprego foi centrado no lugar - pátios externos e internos-, sendo a análise de tais espaços realizados nos períodos de intervalo das turmas, que ocorre de acordo com determinação de cada professor responsável, realizadas em diferentes horários.

Portanto, as análises e avaliações são apresentadas em plantas baixas dos espaços observados, com descrição das atividades realizadas.

\subsection{Poema dos Desejos}

O poema dos desejos caracteriza-se por uma forma de livre expressão, cuja aplicação do instrumento consiste em solicitar aos usuários de um determinado local que descrevam verbalmente ou expressem por meio de desenhos o que teria ou como seria o ambiente ideal para eles (RHEINGANTZ, AZEVEDO, 2008, p.04).

Desta forma, para sua aplicação na avaliação das Creches PROINFÂNCIA selecionadas, foram preparadas folhas com uma frase: "Eu gostaria que a minha creche...". Optou-se por utilizar a técnica de desenhos como respostas pelo fato do método ter sido aplicado com crianças ainda não alfabetizadas.

Ao longo de todo o processo os pesquisadores foram também anotando os comentários que as crianças iam expressando enquanto elaboravam os desenhos, visando a interação entre os participantes e explorar as informações relevantes que emergem espontaneamente durante o processo de coleta dos dados. Esse método foi aplicado 


\section{$16^{\circ}$ \\ ERGODESIGN USIHC CINAHPA}

pelos pesquisadores com as turmas do Pré A em cada creche analisada, com idade compreendida entre 4 a 5 anos. Posteriormente, a compilação dos resultados se deu sobre forma de gráficos, acompanhados das análises realizadas.

\subsection{Questionários}

A aplicação de questionários consiste em aferir, conforme Ornstein (1995 apud GALVÃO, 2007,p.63), a impressão dos usuários sobre determinado produto/ambiente. No caso de APO, os questionários buscam verificar a relação do usuário com o ambiente construído.

Conforme Galvão (2007), saber como os indivíduos, com quem temos contato direto, percebem o ambiente em que vivem: suas satisfações e insatisfações são de suma importância, pois conhecendo a percepção de cada um será possível a realização de um trabalho em bases locais, partindo da sua realidade.

Desta forma, tomou-se como base para a estruturação e elaboração do questionário, o relatório final desenvolvido pelo grupo de pesquisa em Avaliação de Desempenho do Ambiente Construído, no curso de Pós-Graduação em Arquitetura (PROARQ), da Faculdade de Arquitetura e Urbanismo da UFRJ - Universidade Federal do Rio de Janeiro, em junho de 2012.

A metodologia adotada constituiu na aplicação de questionários com o maior número possível de professores e funcionários das creches em análise, verificando-se que, em ambientes de uso comuns, muitos professores e funcionários decidiram responde-lo conjuntamente.

Assim, o questionário foi o instrumento que apresentou maior eficiência na coleta e sintetização das percepções e anseios dos usuários em relação ao ambiente, sendo que no anexo encontra-se o questionário modelo. Os gráficos com as tabulações dos resultados representam a forma como os ambientes da creche ou a creche como um todo foi percebida pelos adultos funcionários da instituição. $16^{\circ}$ Ergodesign - Congresso Internacional de Ergonomia e Usabilidade de Interfaces Humano Tecnológica: Produto, Informações Ambientes Construídos e Transporte

$16^{\circ}$ USIHC - Congresso Internacional de Ergonomia e Usabilidade de Interfaces Humano Computador

CINAHPA | 2017 - Congresso Internacional de Ambientes Hipermídia para Aprendizagem.

\subsection{Tratamento de dados e informações}

Sabe-se que os diferentes métodos de APO podem ser direcionados para diferentes fins, conforme expõe Castro , Lacerda e Penna (2004): para avaliação técnica das condições de funcionamento e do estado de conservação dos componentes e da estrutura de um edifício, para uma avaliação da qualidade e funcionamento do ambiente ou de adequação do ambiente às normas e, por fim, para avaliação da opinião do usuário.

Entretanto, a partir da aplicação de cada um desses métodos, percebe-se que nenhum dos mesmos isoladamente é capaz de averiguar todas as informações necessárias para concretizar a análise (NATALINO, ÁVILA, 2016). Desta forma, a abordagem de diferentes métodos e posteriormente sua confrontação e cruzamento dos dados coletados permite uma maior precisão e riqueza da análise.

Desta forma, o tratamento e tabulação dos dados não constitui-se de uma tarefa fácil. Foi necessário que todo o material bruto coletado fosse averiguado isoladamente, por escola, para posteriormente o grupo reunir-se e confrontar as informações coletadas.

Assim, os pesquisadores perceberam quais eram as informações relevantes para se considerar na elaboração de um projeto escolar para os anos iniciais, e puderam categorizar as informações de acordo com as prioridades dos usuários e possibilidades de serem efetivamente realizadas a curto, médio e longo prazo.

\section{Apresentação preliminar dos resultados}

A análise realizada possibilitou vislumbrar diversos aspectos que podem vir a ser transformados para melhorar a qualidade do ambiente construído.

Durante a análise walktrough, constatou-se inicialmente, a não adequação do modelo PROINFÂNCIA a região em estudo, tendo em vista as variáveis climáticas e estações do ano bem definidas, resultando em soluções provisórias e/ou 


\section{$16^{\circ}$ \\ ERGODESIGN USIHC CINAHPA}

permanentes para amenizar o desconforto térmico apresentado em dias frios ou chuvosos. Constatouse na oportunidade também, a adaptação das salas para novos fins, contrários ao que pode ser verificado na planta original do projeto, a exemplo de salas transformadas em depósitos ou copa de professores usufruída como sala de reuniões.

Tais dados são oriundos da ficha de inventário ambiental e checklist realizados, que foram sintetizados em um quadro, de acordo com os aspectos avaliados: estético-compositivos, técnicos-construtivos, contextuais-ambientais fatores externos, conforto climático e acessibilidade- e aspectos programáticosfuncionais.

Na observação indireta realizada, visando a criação dos mapas comportamentais dos espaços de recreação registrou-se uma maior dificuldade de compreensão e análise, uma vez que tais espaços não são frequentemente utilizados, visto carência de mobiliário e mobiliários com alturas não adaptadas as crianças, precariedade dos espaços livres bem como interferência acústica nas demais salas de aula.

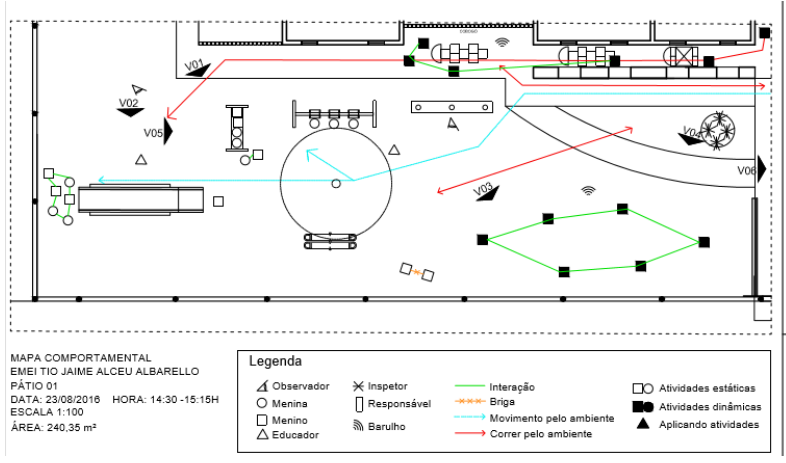

Figura 02: Exemplo de mapa comportamental desenvolvido durante a investigação - análise por pátios. Fonte: dados da pesquisa, 2016.

Na aplicação da técnica Poema dos Desejos, a compilação dos dados ocorreu inicialmente pela distinção dos desenhos em quatro grande grupos:

(a) Ambiente físico - espaços internos, espaços externos, ginásio, campo de futebol...-, (b) Elementos concretos e lúdicos - brinquedos, música, doces, avião-, (c) Figuras humanas: $16^{\circ}$ Ergodesign - Congresso Internacional de Ergonomia e Usabilidade de Interfaces Humano Tecnológica: Produto, Informações Ambientes Construídos e Transporte

$16^{\circ}$ USIHC - Congresso Internacional de Ergonomia e Usabilidade de Interfaces Humano Computador

CINAHPA | 2017 - Congresso Internacional de Ambientes Hipermídia para Aprendizagem.

pai/mãe, ele próprio, colegas, educadores/funcionários...), (d) Elementos da natureza (água, animais, árvores e plantas...) e, posteriormente, pelo desenvolvimento de gráficos a fim de facilitar o processo de análise.

Assim, observou-se que, ao solicitar que a criança desenhasse suas expectativas referentes a escola, muitas vezes foram registrados elementos lúdicos e concretos, como personagens de histórias infantis e brinquedos, frutos do imaginário infantil (figura 03). Elementos como campos de futebol (figura 04), piscina de bolinha, playground também foram bem representados pelas crianças, podendo ser justificado pela ausência de espaços qualificados para o brincar.

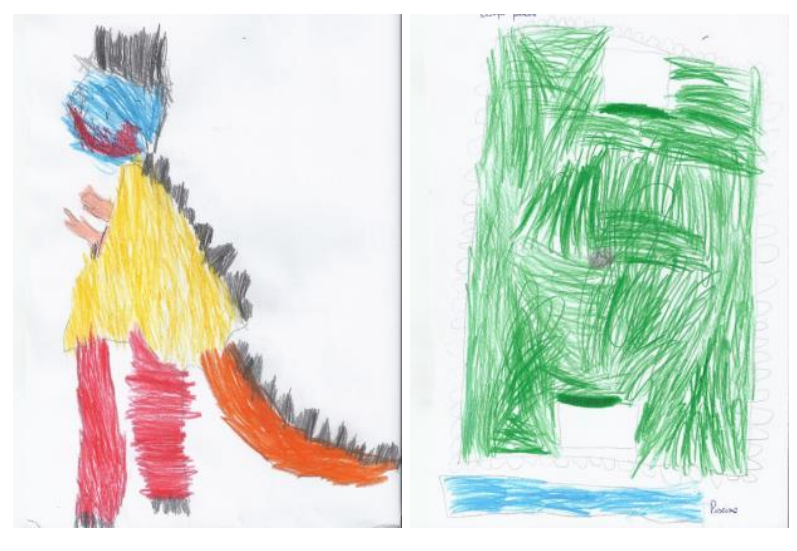

Figuras 03 e 04: Desenhos representando o anseio das crianças. Fonte: dados da pesquisa,2016.

No que tange aos questionários, a aplicação destes se deu com os professores e funcionários presentes nas escolas no dia da investigação. Considerando as quatro creches analisadas, aplicaram-se 63 questionários no total, de forma a levantar os principais aspectos positivos e negativos da escola. Tendo em vista que cada creche-escola apresenta peculiaridades e necessidades que diferem, em função dos diferentes condicionantes, pode-se ressaltar no entanto a carência em ambas as instituições de mais salas de aula ou maior dimensionamento das mesmas, e de uma pavilhão coberto para a realização de atividades dinâmicas. Da mesma forma, o fator com grande avaliação positiva são os alunos, ressaltando os laços de amizade e boa convivência entre professores/funcionários e crianças das instituições
Realização:

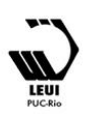




\section{$16^{\circ}$ \\ ERGODESIGN USIHC CINAHPA}

$16^{\circ}$ Ergodesign - Congresso Internacional de Ergonomia e Usabilidade de Interfaces Humano Tecnológica: Produto, Informações Ambientes Construídos e Transporte

$16^{\circ}$ USIHC - Congresso Internacional de Ergonomia e Usabilidade de Interfaces Humano Computador

CINAHPA | 2017 - Congresso Internacional de Ambientes Hipermídia para Aprendizagem. investigadas.

\section{Considerações finais}

O objetivo da realização desta APO, era identificar as principais dificuldades na implantação de projetos do programa PROINFÂNCIA em diferentes municípios utilizando quatro principais técnicas de analises, as quais já apresentadas. Cada uma destas técnicas possibilitou a percepção de diferentes problemáticas, através do ponto de vista dos pesquisadores, funcionários, professores e alunos, deixando claras as necessidades de cada um.

Os resultados encontrados evidenciaram a necessidade de maior preocupação com a adaptabilidade de projetos padrões em diferentes regiões do país, tendo em vista principalmente a variação climática de cada região, a qual influencia diretamente nas atividades realizadas nos espaços de ensino.

Ao que se refere ao planejamento de ambientes escolares, é de grande valia que estes realmente sejam pensados para a relação usuário- ambiente, buscando salientar influência direta que o espaço físico aplica no processo de aprendizado, fato ampliado quando se trata da educação infantil, que faz uso do lúdico e do entretenimento como formas de ensino, tendo assim a necessidade de que o corpo físico escolar disponha de recursos para que tais atividades sejam realizadas com conforto e praticidade em todas as fases de aprendizado.

A partir de tais percepções, busca-se evidenciar a necessidade de realizar-se uma releitura constante dos projetos executados, de modo a identificar os pontos positivos e negativos do mesmo, para evitar a repetição de soluções mal sucedidas, afinal, como afirma Paulo Mendes da Rocha, "o projeto ideal não existe, a cada novo projeto existe a oportunidade de realizar uma aproximação."

\section{BIBLIOGRAFIA}

BRASIL. Fundo Nacional de Desenvolvimento Educacional - Proinfância. Brasília, 2012.

Disponível em: <http://www.fnde.gov.br/programas/proinfancia/pr oinfancia-projetos-arquitetonicos-paraconstrucao/proinfancia-tipoc> Acesso em 23 de agosto de 2016.

BRASIL. Lei No 8.069, DE 13 DE JULHO DE 1990 - Estatuto da Criança e do Adolescente. Disponível em: <

http://www.planalto.gov.br/ccivil_03/leis/L8069Co mpilado.htm> Acesso em 21 de agosto de 2016

CAMBIAGHI, S. Desenho Universal: Métodos e técnicas para arquitetos e urbanistas. São Paulo: Editora Senac São Paulo, 2007

CASTRO,J.; LACERDA,L.; PENNA,A.C. Avaliação Pós-Ocupação: saúde nas edificações da FIOCRUZ. Rio de Janeiro: FIOCRUZ,2004, $115 \mathrm{p}$.

GALVÃO, W.J.F. COPAN/SP: A trajetória de um mega empreendimento, da concepção ao uso: estudo compreensivo do processo com base na avaliação pós-ocupação. São Paulo: Dissertação de Mestrado - Universidade de São Paulo, 2007.

NATALINO, Maria Luiza Rodrigues; ÁVILA, Vinícius Martins; "Avaliação pós-ocupação de projeto padrão PROINFÂNCIA: uma abordagem multimétodos no CMEI - Espaço da Infância", p. 631-642 . In: Anais do VI Encontro Nacional de Ergonomia do Ambiente Construído \& VII Seminário Brasileiro de Acessibilidade Integral [=Blucher Design Proceedings, v.2 n.7]. São Paulo: Blucher, 2016.

MARCELINO, M.M. O. P. Arquitetura escolar infantil modulada e flexível. Natal: Dissertação de Mestrado em Arquitetura/ UFRN, 2014.

Disponível em: <

https://repositorio.ufrn.br/jspui/handle/123456789/

19313> Acesso em 20 de agosto de 2016.

RHEINGANTZ P.; AZEVEDO, G. et al.

Observando a qualidade do Lugar: procedimentos para a Avaliação Pós-Ocupação. Rio de Janeiro: Universidade Federal do Rio de Janeiro, Faculdade de Arquitetura e Urbanismo, Pós-Graduação em Arquitetura, 2008. Disponível
Realização:

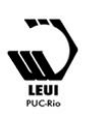




\section{$16^{\circ}$ \\ ERGODESIGN USIHC CINAHPA}

$16^{\circ}$ Ergodesign - Congresso Internacional de Ergonomia e Usabilidade de Interfaces Humano Tecnológica: Produto, Informações Ambientes Construídos e Transporte

$16^{\circ}$ USIHC - Congresso Internacional de Ergonomia e Usabilidade de Interfaces Humano Computador

CINAHPA | 2017 - Congresso Internacional de Ambientes Hipermídia para Aprendizagem.

em: <www.fau.ufrj/prolugar.> Acesso em 20 de agosto de 2016

TAVARES, R. Avaliação de desempenho do ambiente construído. Rio de Janeiro: Programa de pós-graduação em Arquitetura, 2012

\section{Agradecimentos}

As instituições de ensino infantil PROINFÂNCIA dos quatro municípios em análise pela boa receptividade e colaboração com o desenvolvimento deste trabalho. 